\title{
Copper-Catalysed Multicomponent Click Synthesis of 5-Alkynyl 1,2,3-Triazoles under Ambient Conditions
}

\author{
Francisco Alonso, ${ }^{\text {a }}$ Yanina Moglie, ${ }^{\mathrm{a}}$ Gabriel Radivoy, ${ }^{\mathrm{b}}$ Miguel Yus ${ }^{\mathrm{a}}$ \\ a Departamento de Química Orgánica, Facultad de Ciencias and Instituto de Síntesis Orgánica (ISO), Universidad de Alicante, Apdo. 99 , \\ 03080 Alicante, Spain \\ Fax +34(965)903549; E-mail: falonso@ua.es \\ b Departamento de Química, Instituto de Química del Sur (INQUISUR-CONICET), Universidad Nacional del Sur, Avenida Alem 1253 , \\ 8000 Bahía Blanca, Argentina
}

Received: 02.05.2012; Accepted after revision: 24.06.2012

Dedicated to the memory of Professor Guy Solladié

\begin{abstract}
Copper(I) oxide has been found to effectively catalyse the multicomponent click synthesis of fully substituted 5-alkynyl 1,2,3-triazoles from organic halides, sodium azide, and terminal alkynes in methanol under ambient conditions.
\end{abstract}

Key words: alkynes, alkyl halides, azides, cycloaddition, copper, cross-coupling, heterocycles, multicomponent reaction

In the dawn of the $21^{\text {st }}$ century, we have witnessed a revival of interest in the Huisgen 1,3-dipolar cycloaddition reaction of organic azides and alkynes ${ }^{1}$ after the pivotal discovery by the groups of Meldal $^{2}$ and Sharpless. ${ }^{3}$ Copper(I) catalysis was found to dramatically accelerate the reaction under mild conditions while achieving a high regioselectivity towards the 1,4-regioisomer of the triazole product. This powerful, highly reliable, and selective reaction is the paradigm of a click reaction, as it meets the set of stringent criteria required in click chemistry as defined by Sharpless et al. ${ }^{4}$ Consequently, this protocol has found increasing application in a variety of disciplines such as organic chemistry, drug discovery and medicinal chemistry, polymer and materials science, or bioconjugation. $^{5}$

The copper-catalysed azide-alkyne cycloaddition $(\mathrm{Cu}-$ AAC) provides a direct entry into 1,4-disubstituted 1,2,3triazoles, whereas the formation of the 1,4,5-trisubstituted derivatives relies on the use of ruthenium catalysts ${ }^{6}$ or modification of preformed 1,2,3-triazoles. ${ }^{7}$ In the latter context, three different approaches have been devised for the introduction of substituents at the 5-position of the triazole unit, namely: (a) the interception of stoichiometrically functionalised 5-cuprated-1,2,3-triazoles, (b) the use of stoichiometrically functionalised terminal alkynes, and (c) the catalytic direct functionalisation of $\mathrm{C}-\mathrm{H}$ bonds. ${ }^{7}$

The synthesis of 5-alkynyl 1,2,3-triazoles has been mainly accomplished following the first approach. Wu et al. described thus the copper-mediated synthesis of fully substituted 1,2,3-triazoles by reacting organic azides and

SYNLETT 2012, 23, 000A-000D

Advanced online publication: 08.08.2012

DOI: 10.1055/s-0031-1290445; Art ID: ST-2012-D0385-L

(C) Georg Thieme Verlag Stuttgart · New York terminal alkynes with stoichiometric $\mathrm{CuI}$ and triethylamine, using $\mathrm{ICl}$ as a trapping agent of the intermediate copper(I) triazolide. ${ }^{8 a}$ The corresponding 5-iodo-1,2,3-triazoles were further subjected to the palladium-catalysed Sonogashira-Hagihara cross-coupling reaction with terminal alkynes, giving rise to 5-alkynyl 1,2,3-triazoles. ${ }^{8 \mathrm{~b}} \mathrm{~A}$ more direct strategy to access this type of compounds was reported by Porco's group, in which, organic azides and terminal alkynes reacted in a catalytic system comprised of $\mathrm{Cu}(\mathrm{MeCN})_{4} \mathrm{PF}_{6}, N, N, N^{\prime}$-trimethylethylenediamine as ligand, Hünig's base, molecular oxygen, and 4-methylmorpholine $N$-oxide as co-oxidant in dichloromethane. ${ }^{9}$ As noted by the authors, the Glaser coupling and cycloaddition towards the nonalkynylated 1,4-disubstituted triazoles were competing reactions which accounted for the low yields attained in many cases. Soon after, Chen et al. presented the 1,3-dipolar cycloaddition-coupling reaction of terminal alkynes, phenylboronic acids, and sodium azide catalysed by $\mathrm{CuI}(10 \mathrm{~mol} \%)$ and $\mathrm{CuSO}_{4} \cdot 5 \mathrm{H}_{2} \mathrm{O}$ (20 mol\%) in 1,4-dioxane-water. ${ }^{10}$ Disubstituted 1 -aryl5-alkynyl 1,2,3-triazoles have been prepared, in an indirect manner, through the cycloaddition of 2-morpholinobut-1-en-3-yne with aryl azides. ${ }^{11}$ Due to our ongoing interest in click chemistry ${ }^{12}$ and to the scant number of methodologies that enable the formation of 5-alkynyl 1,2,3-triazoles in an efficient manner, we want to present herein the first general methodology for the copper-catalysed multicomponent synthesis of 5-alkynyl-1,4-disubstituted 1,2,3-triazoles starting from organic halides, terminal alkynes, and sodium azide under ambient conditions.

The reaction of benzyl bromide (1a), phenylacetylene (2a), and sodium azide in the presence of a copper source was used as a model reaction in order to optimise the catalytic system and conditions (Table 1). It is worth noting that, among the organic solvents tested (toluene, $\mathrm{CH}_{2} \mathrm{Cl}_{2}$, $\mathrm{MeCN}, \mathrm{THF}, \mathrm{H}_{2} \mathrm{O}$, EtOH, and $\mathrm{MeOH}$ ), exclusively methanol gave the desired product 3aa. In fact, the presence of methanol seems to be crucial for the reaction to take place as we never detected this product in our previous research on click chemistry. ${ }^{12}$ Interestingly, the reaction proceeded at room temperature irrespective of the copper source at 
Table 1 Screening of the Catalysts in the Synthesis of $\mathbf{3} \mathbf{a a}^{\mathrm{a}}$

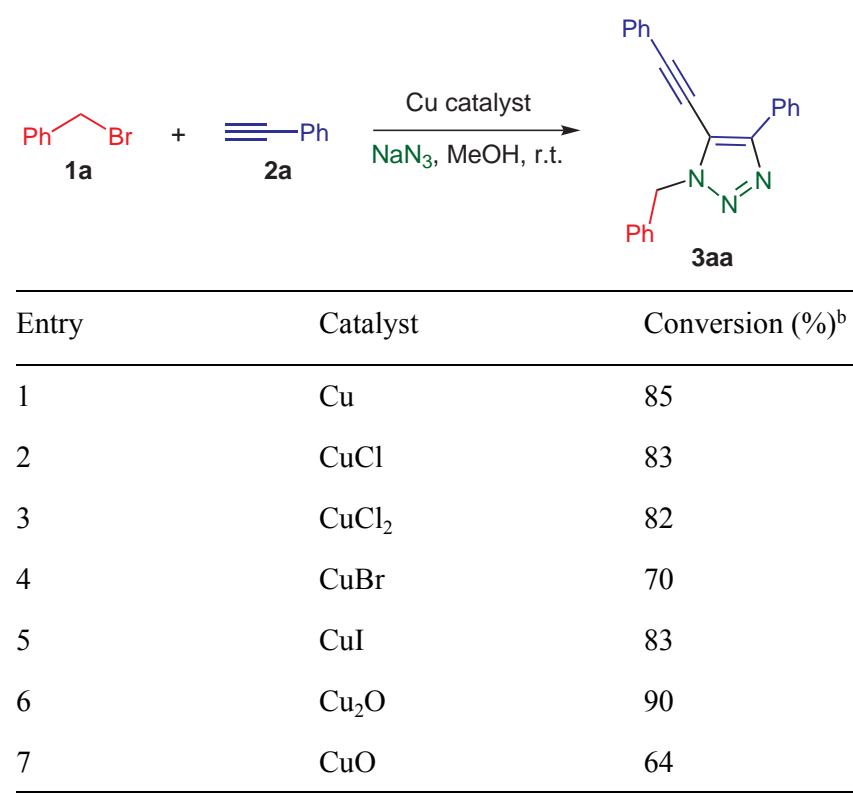

${ }^{\mathrm{a}}$ Reaction conditions: $\mathbf{1 a}(0.5 \mathrm{mmol}), \mathbf{2 a}(1.0 \mathrm{mmol}), \mathrm{NaN}_{3}(0.6 \mathrm{mmol})$, catalyst $(0.01 \mathrm{mmol}), \mathrm{MeOH}(2 \mathrm{~mL})$, r.t.

${ }^{\mathrm{b}}$ Conversion into 3aa after $24 \mathrm{~h}$ determined by GC.

low catalyst loading, though $\mathrm{Cu}_{2} \mathrm{O}$ exhibited the highest performance (Table 1 , entry 6 ).

Following the optimised conditions, an array of 5-alkynyl-1,4-disusbstituted 1,2,3-triazoles were synthesised (Scheme 1). Electronically different benzyl bromides and chlorides 1a-f reacted with phenylacetylene (2a) to furnish the corresponding products $\mathbf{3 a a}-\mathbf{f a}$ in moderate to high yields. Allylic bromides and ethyl 2-bromoacetate reacted smoothly and high yielding, giving rise to $\mathbf{3 g a}$, 3ha, and 3ia, respectively. Electron-neutral, -rich, and -deficient aryl acetylenes $\mathbf{2 b}-\mathbf{d}$ behaved similarly when combined with benzyl bromide (1a). Moreover, triazoles bearing two aliphatic substituents at the 4,5-positions (3ae-ag) were also efficiently obtained.

It is worth noting that products $\mathbf{3}$ can be considered the result of the Huisgen 1,3-dipolar cycloaddition over symmetrically substituted 1,3-diynes. This reaction has been barely studied due to the lack of selectivity; the thermal conditions applied require specific sterically demanding substrates in order to prevent the double cycloaddition and polymerisation side reactions, and even then, the yields reported were rather poor. ${ }^{13}$ This kind of process was discarded in our methodology as the reaction of 1,4-diphenylbuta-1,3-diyne with benzyl bromide and sodium azide, under the standard conditions, led to the unchanged starting diyne and benzyl azide. The possibility of carbonhydrogen bond activation at the 5-position of the parent 1,4-disubstituted triazole was also ruled out because the reaction of 1-benzyl-4-phenyl-1H-1,2,3-triazole with phenylacetylene also failed. These results, together with the experiment depicted in Scheme 2, involving equimolecular amounts of 1a and $\mathbf{2 a}$ in $\mathrm{CD}_{3} \mathrm{OD},{ }^{14}$ point to a copper(I) triazolide ${ }^{3,15}$ as the most plausible precursor of both deuterated 4aa and compounds 3 after protonationdeuteration or coupling with the alkyne, respectively.

Synlett 2012, 23, A-D
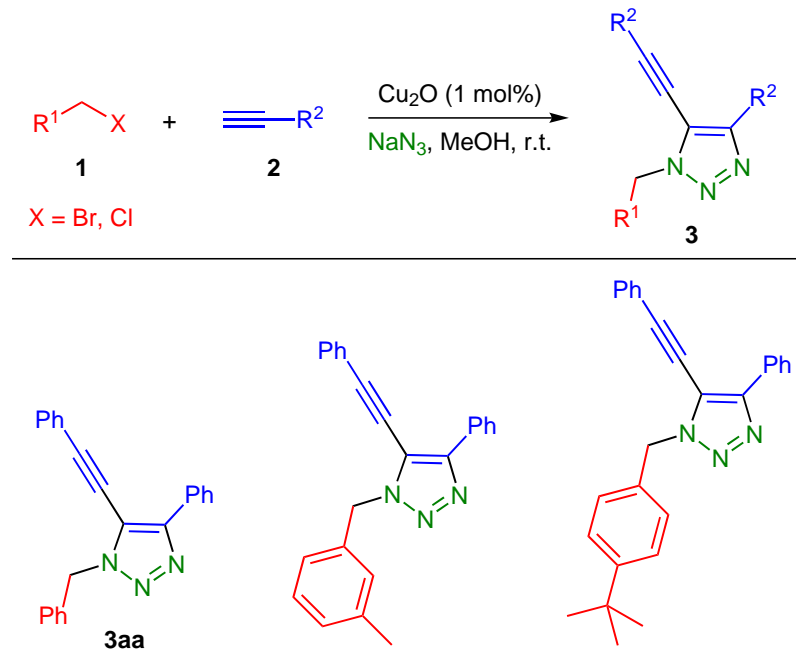

$(\mathrm{X}=\mathrm{Br}, 6 \mathrm{~h}, 87 \%)$

$(\mathrm{X}=\mathrm{Cl}, 16 \mathrm{~h}, 81 \%)$
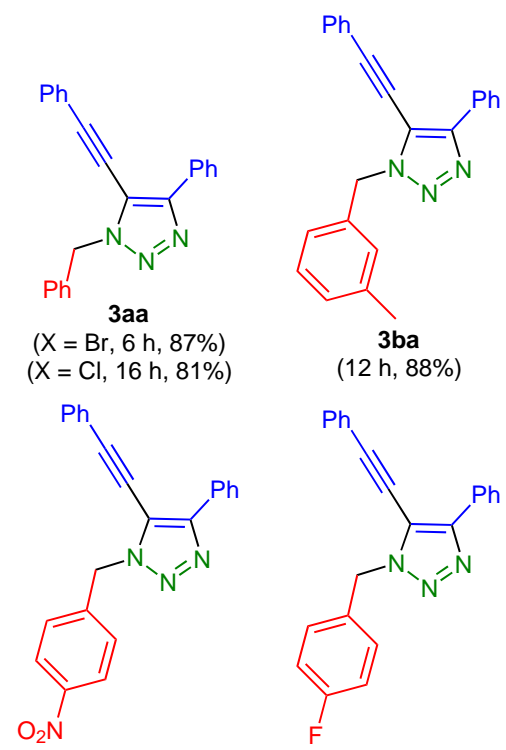

3 ba

$(12$ h, $88 \%)$

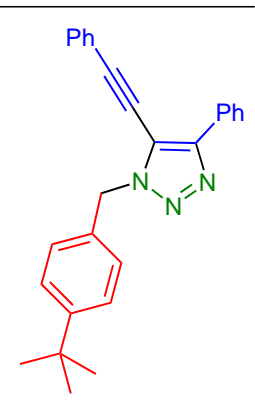

3 ca

(24 h, 50\%)

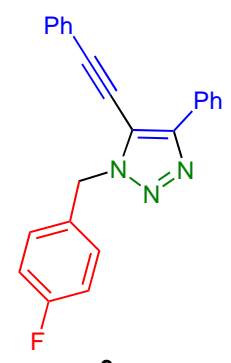

3ea

$(12 \mathrm{~h}, 68 \%)$

(12 h, 65\%)

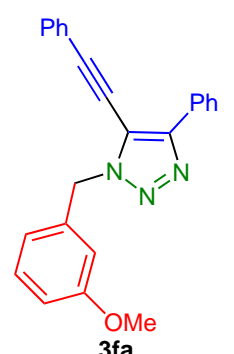

(X $=\mathrm{Cl}, 12 \mathrm{~h}, 56 \%)$
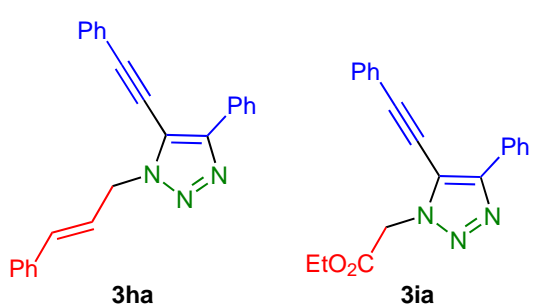

(8h, $87 \%$ )

(8 h, 82\%)

$$
\begin{gathered}
\text { 3ga } \\
(8 \mathrm{~h}, 90 \%)
\end{gathered}
$$<smiles>[R]c1ccc(C#Cc2c(-c3ccc([R])cc3)nnn2Cc2ccccc2)cc1</smiles>

$\mathrm{R}=$ Me, 3ab (12 h, 80\%) $\mathrm{R}=$ OMe, 3ac $(12 \mathrm{~h}, 81 \%)$ $\mathrm{R}=\mathrm{CF}_{3}$, 3ad (12 h, 78\%)

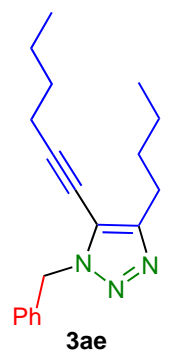

$3 \mathrm{ae}$
$(8 \mathrm{~h}, 83 \%)$

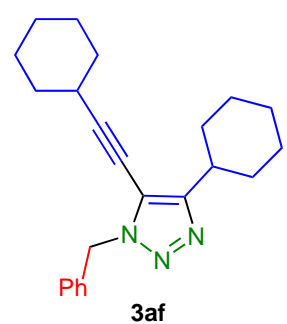

(24 h, 54\%)

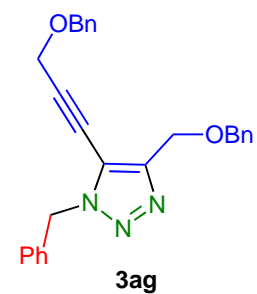

3ag
$(12 \mathrm{~h}, 72 \%)$

Scheme 1 Multicomponent synthesis of fully substituted 5-alkynyl 1,2,3-triazoles catalysed by $\mathrm{Cu}_{2} \mathrm{O}$. Reagents and conditions: $\mathbf{1}(0.5$ $\mathrm{mmol}), 2$ (1.0 mmol), $\mathrm{NaN}_{3}(0.6 \mathrm{mmol}), \mathrm{Cu}_{2} \mathrm{O}(1.4 \mathrm{mg}, 1 \mathrm{~mol} \% \mathrm{re}-$ ferred to 2$), \mathrm{MeOH}(2 \mathrm{~mL})$, r.t. Reaction time and isolated yield in parenthesis. $\mathrm{X}=\mathrm{Br}$ unless otherwise stated 


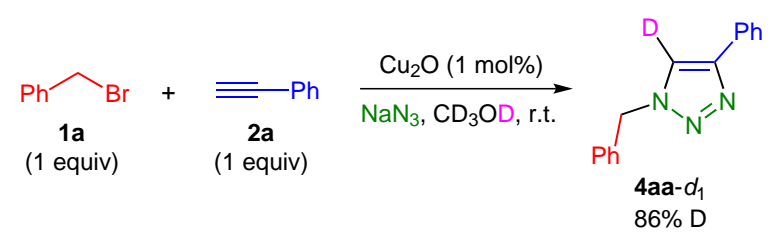

Scheme 2 Deuterium-labelling experiment

In order to get an insight into the reaction mechanism, reagent-grade $\mathrm{MeOH}$ (99.8\%), anhydrous $\mathrm{MeOH}(99.8 \%$, $<0.002 \%$ water), and $\mathrm{CD}_{3} \mathrm{OD}$ were used as solvents under different atmospheres in the title reaction. Conversions $>80 \%$ into 3aa, without byproduct formation, were only achieved under the standard conditions (i.e., in the presence of air) independently of the methanol utilised. In contrast, when the above solvents were subjected to degasification, prior to the reaction, 3aa was produced in 1$9 \%$. Finally, substantial amounts of alkyne homocoupling (21-25\%) together with 3aa (67-70\%) were recorded in the presence of molecular oxygen (balloon). From these results it can be inferred that the oxygen dissolved is oxidising copper in the catalytic cycle (Scheme 3). Given that the reductive elimination from copper(II) species is an unfavoured process, ${ }^{16}$ oxidation of copper(II) to copper(III) and subsequent reductive elimination, ${ }^{17}$ with regeneration of copper(I), is invoked as similarly suggested by Porco et al. ${ }^{9}$ In addition, the equilibrium solubility of oxygen in methanol seems to be the ideal one to drive the reaction selectively toward the fully substituted triazole, making unnecessary the use of a chemical oxidant.

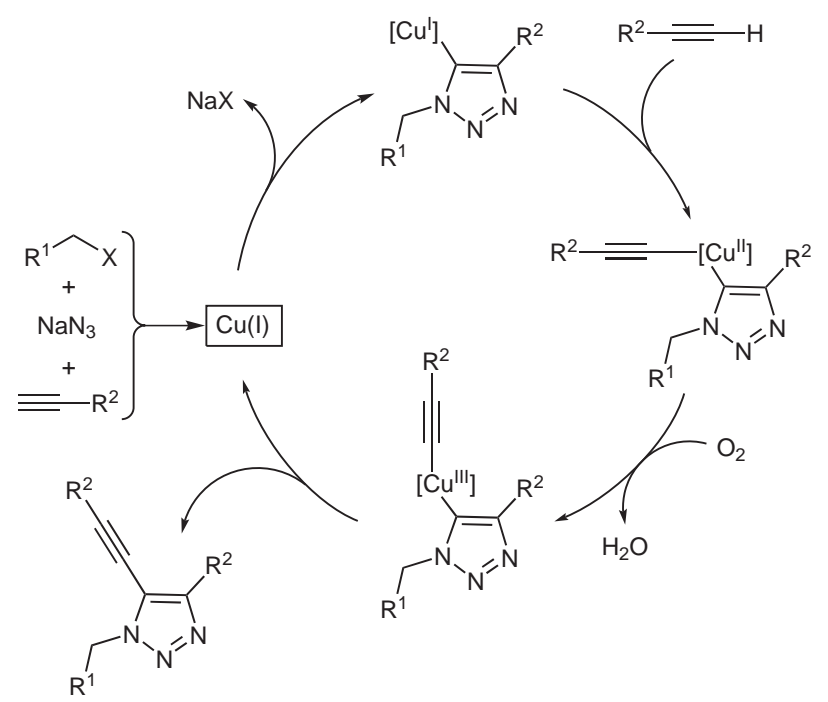

Scheme 3 Proposed catalytic cycle

In conclusion, a straightforward synthesis of fully substituted 1,2,3-triazoles with an alkynyl moiety at the 5-position has been successfully introduced from organic halides, terminal alkynes, and sodium azide, using a very simple catalytic system composed of copper(I) oxide and methanol under ambient conditions. ${ }^{18}$ This discovery will be of great interest for the varied disciplines dealing with click chemistry. Further research on the mechanism, scope, and applications of this multicomponent reaction are under way. In particular, the introduction of other substituents at the 5-position will be especially challenging.

\section{Acknowledgment}

This work was generously supported by the Spanish Ministerio de Ciencia e Innovación (MICINN; CTQ2007-65218 and Consolider Ingenio 2010-CSD2007-00006), the Generalitat Valenciana (GV; PROMETEO/2009/039), and Fondo Europeo de Desarrollo Regional (FEDER). Y. M. acknowledges the Instituto de Síntesis Orgánica (ISO) of the Universidad de Alicante for a grant.

Supporting Information for this article is available online at http://www.thieme-connect.com/ejournals/toc/synlett.

\section{References and Notes}

(1) (a) Huisgen, R.; Knorr, R.; Moebius, L.; Szeimies, G. Chem. Ber. 1965, 98, 4014. (b) Huisgen, R. Pure Appl. Chem. 1989, $61,613$.

(2) Tornøe, C. W.; Christensen, C.; Meldal, M. J. Org. Chem. 2002, 67, 3057.

(3) Rostovtsev, V. V.; Green, L. G.; Fokin, V. V.; Sharpless, K. B. Angew. Chem. Int. Ed. 2002, 41, 2596.

(4) For a review, see: Kolb, H. C.; Finn, M. G.; Sharpless, K. B. Angew. Chem. Int. Ed. 2001, 40, 2004.

(5) For selected recent reviews and monographs, see: (a) Meldal, M.; Tornøe, C. W. Chem. Rev. 2008, 108, 2952. (b) Appukkuttan, P.; Van der Eycken, E. Eur. J. Org. Chem. 2008, 1133. (c) Amblard, F.; Cho, J. H.; Schinazi, R. F. Chem. Rev. 2009, 109, 4207. (d) Click Chemistry for Biotechnology and Materials Science; Lahann, J., Ed.; John Wiley and Sons: Hoboken, 2009. (e) Finn, M. G.; Fokin, V. V. In Catalysis Without Precious Metals; Morris Bullock, R., Ed.; Wiley-VCH: Weinheim, 2010, 235-260. (f) For a special issue on applications of click chemistry, see: Chem. Soc. Rev. 2010, 39, issue 4. (g) Quin, A.; Lam, J. W. Y.; Tang, B. Z. Chem. Soc. Rev. 2010, 39, 2522. (h) AragãoLeoneti, V.; Campo, V. L.; Gomes, A. S.; Field, R. A.; Carvalho, I. Tetrahedron 2010, 66, 9475.

(6) Boren, B. C.; Narayan, S.; Rasmussen, L. K.; Zhang, L.; Zhao, H.; Lin, Z.; Jia, G.; Fokin, V. V. J. Am. Chem. Soc. 2008, 130, 8923.

(7) For a perspective, including the synthesis of 5-halotriazoles, see: Ackermann, L.; Potukuchi, H. K. Org. Biomol. Chem. 2010, $8,4503$.

(8) (a) Wu, Y.-M.; Deng, J.; Li, Y.; Chen, Q.-Y. Synthesis 2005, 1314. (b) Deng, J.; Wu, Y.-M.; Chen, Q.-Y. Synthesis 2005, 2730.

(9) Gerard, B.; Ryan, J.; Beeler, A. B.; Porco, J. A. Jr. Tetrahedron 2006, 62, 6405.

(10) Yang, D.; Fu, N.; Liu, Z.; Li, Y.; Chen, B. Synlett 2007, 278.

(11) Brunner, M.; Maas, G.; Klärner, F.-G. Helv. Chim. Acta 2005, $88,1813$.

(12) (a) Alonso, F.; Moglie, Y.; Radivoy, G.; Yus, M. Tetrahedron Lett. 2009, 50, 2358. (b) Alonso, F.; Moglie, Y.; Radivoy, G.; Yus, M. Eur. J. Org. Chem. 2010, 1875. (c) Alonso, F.; Moglie, Y.; Radivoy, G.; Yus, M. Adv. Synth. Catal. 2010, 352, 3208. (d) Alonso, F.; Moglie, Y.; Radivoy, G.; Yus, M. Org. Biomol. Chem. 2011, 9, 6385. (e) Alonso, F.; Moglie, Y.; Radivoy, G.; Yus, M. J. Org. Chem. 2011, 76, 8394. (f) Alonso, F.; Moglie, Y.; Radivoy, G.; Yus, M. Heterocycles 2012, 84, 1033. 
(13) (a) Stepanova, N. P.; Orlova, N. A.; Galishev, V. A. Turbanova, E. S.; Petrov, A. A. Zh. Org. Khim. 1985, 21, 979; Chem. Abstr. 1985, 103, 123415. (b) Bettison, M.; Hitchcock, P. B.; Walton, D. R. M. J. Organomet. Chem. 1988, 341, 247. (c) Domnin, I. N.; Remizova, L. A.; Starova, G. L.; Rominger, F. Russ. J. Org. Chem. 2009, 45, 1678.

(14) 1,4-Disubstituted triazoles 4 are not formed, but only triazoles $\mathbf{3}$, when the organic halide $\mathbf{1}$ and the alkyne $\mathbf{2}$ are used in a 1:2 molar ratio. This fact is indicative of the high selectivity of the reaction.

(15) Nolte, C.; Mayer, P.; Straub, B. F. Angew. Chem. Int. Ed. 2007, 46, 2101

(16) See, for instance: Lam, P. Y. S.; Vincent, G.; Bonne, D.; Clark, C. G. Tetrahedron Lett. 2003, 44, 4927.

(17) For the recent observation of $\mathrm{Cu}(\mathrm{I}) / \mathrm{Cu}(\mathrm{III})$ redox steps in cross-coupling reactions, see: Casitas, A.; King, A. E.; Parella, T.; Costas, M.; Stahl, S. S.; Ribas, X. Chem. Sci. 2010, $1,326$.

(18) General Procedure for the Synthesis of 5-Alkynyl 1,2,3triazoles 3

The organic halide $(1,0.5 \mathrm{mmol})$, alkyne $(2,1.0 \mathrm{mmol})$, and $\mathrm{NaN}_{3}(39.0 \mathrm{mg}, 0.6 \mathrm{mmol})$ were added to a reactor tube containing a suspension of $\mathrm{Cu}_{2} \mathrm{O}(1.4 \mathrm{mg}, 0.01 \mathrm{mmol})$ in $\mathrm{MeOH}(2 \mathrm{~mL})$. The reaction mixture was stirred at r.t. without the exclusion of air and monitored by TLC, GLC, and/or ${ }^{1} \mathrm{H}$ NMR spectroscopy until total conversion of the starting materials. $\mathrm{H}_{2} \mathrm{O}(2 \mathrm{~mL})$ was added to the mixture, followed by extraction with EtOAc $(3 \times 10 \mathrm{~mL})$. The resulting organic phase was evaporated under vacuum, and the residue was purified by column chromatography (silica gel, hexane-EtOAc).

\section{1-Benzyl-4-(p-tolyl)-5-(p-tolylethynyl)-1H-1,2,3-triazole} (3ab)

Starting from benzyl bromide (1a, $60 \mu \mathrm{L}, 0.5 \mathrm{mmol})$, 1ethynyl-4-methylbenzene (2b, $127 \mu \mathrm{L}, 1.0 \mathrm{mmol}), \mathrm{NaN}_{3}$ ( $39.0 \mathrm{mg}, 0.6 \mathrm{mmol}$ ), and $\mathrm{Cu}_{2} \mathrm{O}(1.4 \mathrm{mg}, 0.01 \mathrm{mmol})$ in $\mathrm{MeOH}(2 \mathrm{~mL}), \mathbf{3 a b}$ was isolated as a pale orange solid (145 $\mathrm{mg}, 80 \%$ ); $\mathrm{mp} 81.9-84.0^{\circ} \mathrm{C} ; R_{f}=0.66$ (hexane-EtOAc $=$ 7:3). IR (neat): $v=3034,2919,1518,1496,1455,1362$, $1001,815,726,692 \mathrm{~cm}^{-1}$. ${ }^{1} \mathrm{H}$ NMR (300 MHz, $\left.\mathrm{CDCl}_{3}\right)$ : $\delta=8.07(\mathrm{~d}, J=8.1 \mathrm{~Hz}, 2 \mathrm{H}), 7.42-7.30(\mathrm{~m}, 7 \mathrm{H}), 7.25(\mathrm{~d}$, $J=8.1 \mathrm{~Hz}, 2 \mathrm{H}), 7.21(\mathrm{~d}, J=8.1 \mathrm{~Hz}, 2 \mathrm{H}), 5.65(\mathrm{~s}, 2 \mathrm{H}), 2.39$ $(\mathrm{s}, 3 \mathrm{H}), 2.38(\mathrm{~s}, 3 \mathrm{H}) .{ }^{13} \mathrm{C} \mathrm{NMR}\left(75 \mathrm{MHz}, \mathrm{CDCl}_{3}\right): \delta=148.2$, $140.2,138.6,134.9,131.6,129.6,129.5,128.9,128.6$ $128.2,127.6,126.2,118.6,117.2,102.6,77.4,75.3,53.0$, 21.8, 21.5. MS (70 eV): $m / z(\%)=364(11)\left[\mathrm{M}^{+}+1\right), 363$ (39) $\left[\mathrm{M}^{+}\right], 334$ (10), 245 (19), 244 (100), 203 (15), 127 (15), 91 (23). HRMS: $m / z$ calcd for $\mathrm{C}_{25} \mathrm{H}_{21} \mathrm{~N}_{3}: 363.1735$; found: 363.1726 . 